\title{
Another challenge for scientists
}

\section{Laura M Christian1, Hassan R Naqvi1, Christian Schmidt*1,2, David Covarrubias ${ }^{1}$ and Shawn Mathur ${ }^{1}$}

\author{
Address: ${ }^{1}$ Section of Molecular Genetics and Microbiology and Institute for Cellular and Molecular Biology, University of Texas, 1 University \\ Station, A 5000, Austin, TX, 78712, USA and ${ }^{2}$ Molecular Cancer, Biomed Central Ltd., Middlesex House, 34-42 Cleveland Street, London, W1T \\ $4 \mathrm{LB}, \mathrm{UK}$ \\ Email: Laura M Christian - laura.christian@mail.utexas.edu; Hassan R Naqvi - naqvi@mail.utexas.edu; \\ Christian Schmidt* - schmidt102@gmail.com; David Covarrubias - dcovarrubias@mail.utexas.edu; \\ Shawn Mathur - shawn.mathur@mail.utexas.edu \\ * Corresponding author
}

Published: 17 July 2008

Molecular Cancer 2008, 7:63 doi:10.1186/1476-4598-7-63

This article is available from: http://www.molecular-cancer.com/content/7/l/63

(c) 2008 Christian et al; licensee BioMed Central Ltd.

This is an Open Access article distributed under the terms of the Creative Commons Attribution License (http://creativecommons.org/licenses/by/2.0), which permits unrestricted use, distribution, and reproduction in any medium, provided the original work is properly cited.
Received: 3 July 2008

Accepted: 17 July 2008

\begin{abstract}
By nature, scientists contribute to our understanding of nature and ourselves. As communities undergo significant changes, new challenges are presented. Here, we offer alternative views on recent changes in society.
\end{abstract}

Affordable and abundant sources of energy allowed society to prosper and use a fraction of the generated surplus to support research and development according to agreed priorities. Available resources allowed the scientific community to bloom and use self-evaluation mechanisms to determine areas of funded research. At this point, involvement of scientists in procedures, designed to allocate a generated surplus to projects, seemed to be of lower priority, given the vast amount of surplus and how little the scientific community needed to prosper. Now, that true costs of energy sources are more clear, much of the generated surplus has to be re-invested to neutralize environmental effects of energy production, distribution et cetera. This reduced overall surplus is mirrored in a decline in research funding with a resulting 'pruning' of projects and declined 'high-risk' areas of research.

As with the advent of an information era and inter-connected civilizations, advances in knowledge are now considered strategic assets, let alone the translation of readily accessible knowledge into (a) more cost-effective neutralization strategies and (b) areas of immediate concern to allow a sustained and affordable generation of energy. The once seen 'luxury spending' on science can now be seen as a central effort of society to stay competitive in the attraction of brightest scholars and creating new areas for lucrative commerce, all of which leading to a windfall of benefits, if not self-enhancing loops.

So, science spending should be brought to the greater attention of the larger community for debate and prioritysetting. Failure of scientists to exercise their rights and duties as citizens of a community to raise their voices in the debate and prevent funding from dropping below a critical level may ultimately result in the passing of great chances of a community with the ultimate consequence of declining life-standards in case the speed of progress and participation of knowledge-addition falls below the new and significantly higher average contribution of all nations.

In essence, the new rising information era shifts paradigms and priorities alike, hence, challenging scientists to stay at the forefront of not only path-breaking thinking 
but also alerting local and global communities about risks and benefits of fostered spending in innovation.

\section{Conclusion}

The burden of providing adequate funds to allow development of new technique and advance knowledge requires combined effort of nations. It remains to be debated whether science for the sake of science or periodical pruning are two extremes or two sides of one coin.

\section{Competing interests}

LMC, HRN, DC and SM declare that there are no competing interests. CS is deputy editor of Molecular Cancer and receives no remuneration for his efforts.

\section{Authors' contributions}

CS drafted and finalized this paper. HRN discussed ideas with CS that ultimately resulted in this paper and provided insightful critique. LMC, DC and SM assisted in gathering background information.

Publish with Biomed Central and every scientist can read your work free of charge

"BioMed Central will be the most significant development for disseminating the results of biomedical research in our lifetime. " Sir Paul Nurse, Cancer Research UK

Your research papers will be:

- available free of charge to the entire biomedical community

- peer reviewed and published immediately upon acceptance

- cited in PubMed and archived on PubMed Central

- yours - you keep the copyright 